\title{
Article
}

\section{Studying Human Disease Genes in Caenorhabditis elegans: A Molecular Genetics Laboratory Project}

\author{
Elisabeth A. Cox-Paulson, ${ }^{* \dagger}$ Theresa M. Grana, ${ }^{\dagger \ddagger}$ Michelle A. Harris, ${ }^{\S}$ \\ and Janet M. Batzli ${ }^{\S}$
}

*Department of Biology, SUNY College at Geneseo, Geneseo, NY 14454; ${ }^{\ddagger}$ Department of Biological Sciences, University of Mary Washington, Fredericksburg, VA $22401{ }^{\S}$ Biology Core Curriculum, University of

Wisconsin-Madison, Madison, WI 53706

Submitted June 7, 2011; Revised February 10, 2012; Accepted February 17, 2012

Monitoring Editor: Gary Reiness

\begin{abstract}
Scientists routinely integrate information from various channels to explore topics under study. We designed a 4-wk undergraduate laboratory module that used a multifaceted approach to study a question in molecular genetics. Specifically, students investigated whether Caenorhabditis elegans can be a useful model system for studying genes associated with human disease. In a largeenrollment, sophomore-level laboratory course, groups of three to four students were assigned a gene associated with either breast cancer (brc-1), Wilson disease (cua-1), ovarian dysgenesis (fshr-1), or colon cancer ( $m l h-1)$. Students compared observable phenotypes of wild-type C. elegans and C. elegans with a homozygous deletion in the assigned gene. They confirmed the genetic deletion with nested polymerase chain reaction and performed a bioinformatics analysis to predict how the deletion would affect the encoded mRNA and protein. Students also performed RNA interference (RNAi) against their assigned gene and evaluated whether RNAi caused a phenotype similar to that of the genetic deletion. As a capstone activity, students prepared scientific posters in which they presented their data, evaluated whether C. elegans was a useful model system for studying their assigned genes, and proposed future directions. Assessment showed gains in understanding genotype versus phenotype, RNAi, common bioinformatics tools, and the utility of model organisms.
\end{abstract}

\section{INTRODUCTION}

Promoting strong scientific thinking skills is a central goal of Biocore, a four-semester honors program at the University of Wisconsin-Madison that provides students with a solid back-

DOI: $10.1187 /$ cbe-11-06-0045

Address correspondence to: Elisabeth A. Cox-Paulson (coxe@ geneseo.edu).

Potential conflict of interest: All authors were involved in both developing and assessing this laboratory activity. It is not our intention to promote this particular laboratory exercise over others that are similar.

${ }^{\dagger}$ These authors contributed equally to this work.

(C) 2012 E. A. Cox-Paulson et al. CBE-Life Sciences Education (C) 2012 The American Society for Cell Biology. This article is distributed by The American Society for Cell Biology under license from the author(s). It is available to the public under an AttributionNoncommercial-Share Alike 3.0 Unported Creative Commons License (http:/ / creativecommons.org/licenses/by-nc-sa/3.0).

"ASCB ${ }^{\circledR}$ " and "The American Society for Cell Biology ${ }^{\circledR}$ " are registered trademarks of The American Society for Cell Biology. ground in central concepts and content in biology (Batzli, 2005). Our goal was to design a laboratory exercise for the second-semester cell biology laboratory (Biocore 304) that would complement the molecular genetics unit in the corresponding lecture course (Biocore 303). In this unit, students learn about DNA replication, transcription, translation, $\mathrm{mu}-$ tagenesis, and regulation of gene expression. Students are typically sophomores who have completed 1 yr of inorganic chemistry, one semester of calculus, and the first semester of Biocore lecture and lab, which covers general concepts in evolution, ecology, and transmission genetics. Additional student demographic information is included in the Materials and Methods section. Our major challenge was to design an activity that allowed students to experience an integrative approach to studying a scientific question in molecular genetics, while also being achievable with 125 students and the instructional staff available. Instructional staff for the course included one instructor per section (two total for the fivesection course), one graduate teaching assistant per section, and a full-time laboratory manager who prepared reagents, set up the labs, and also performed some instruction. 
To accomplish this, we designed a laboratory module that posed the question: Can Caenorhabditis elegans be a good model system for studying the function of an assigned human disease gene? In this laboratory module, students used various approaches, including observation of genetic mutants, RNA interference (RNAi), bioinformatics analysis, and scientific literature research to gather data that were then used to formulate a response to the question at hand. We had five main student learning objectives situated within laboratory course goals and focused on scientific reasoning, inquiry, and communication. The learning objectives were: 1) increased understanding of the relationship between genotype and phenotype, 2) increased understanding of RNAi and appreciation of its utility, 3) increased skills and confidence in using bioinformatics tools, 4) deeper appreciation of the importance of model organisms, and 5) integration of the concepts, skills, and knowledge acquired in this module. Importantly, this unit and its student learning objectives fit well with the National Research Council's (NRC) endorsement of project-based exercises in genomics that include increasing understanding of the central dogma and the genetic basis of disease (NRC, 2003).

C. elegans are particularly well suited for use in undergraduate laboratory activities, including those with high enrollment, for several reasons. First, they are easy and inexpensive to grow. They are maintained on agar plates seeded with nonpathogenic Escherichia coli, and thousands of worms can be cultured on a $60-\mathrm{mm}$ plate. C. elegans strains are available for free or at low cost from the Caenorhabditis Genetics Center (www.cbs.umn.edu/CGC), and some are available at no cost through the Cold Spring Harbor Laboratory (www.silencinggenomes.org). C. elegans can be viewed easily with student-grade stereomicroscopes. Also, their genome is fully sequenced, and gene knockdown can be performed inexpensively and easily using a feeding RNAi approach (see $R N A i$ section). On a less technical note, we have observed that students find C. elegans to be intrinsically appealing and enjoy working with them.

We conducted this laboratory exercise in two semesters, Spring 2007 and Spring 2008, and collected information on perceived and actual student learning gains through pre- and postsurveys and by recording poster grades (students' final project) using a detailed rubric. Our findings indicate that this was a challenging activity that successfully promoted accomplishment of our learning objectives.

\section{COURSE UNIT DESIGN}

Student groups were given the overarching goal of assessing whether C. elegans is a good model system for studying an assigned human disease-associated gene. C. elegans has over 100 genes that are associated with human disease genes, making it a potential model system for investigating the conserved cellular roles of these genes (Culetto and Sattelle, 2000). Each group of three to four students was given a C. elegans mutant that carried a homozygous mutation in a gene orthologous to one implicated in human disease (Table 1). Criteria for how these genes were selected are described in Materials and Methods. The selected genes and the diseases associated with their human orthologues were: brc-1 (early onset breast and ovarian cancer); cua-1 (Wilson disease and Menkes disease, which involve abnormal copper transport, and Hailey-Hailey disease, which involves abnormal calcium transport); $f$ sh $r-1$ (rhabdomyosarcoma and ovarian dysgenesis); and mlh-1 (hereditary nonpolyposis colon cancer). This activity was conducted over $4 \mathrm{wk}$ and involved two meetings per week. One meeting was a 50-min session generally used for discussion, and the other was a 3-h laboratory session that met 1-2 d later (a detailed schedule is provided under Laboratory Activity Schedule).

\section{Introduction and Observation of Wild-Type and Mutant C. elegans}

The activity began with a discussion of the utility of C. elegans as a model system and an overview of the laboratory exercise (Supplemental Material A contains the 2008 laboratory manual). During the first and second weeks, students had several opportunities to observe wild-type $C$. elegans and $C$. elegans with a homozygous deletion in their assigned gene using student-grade stereomicroscopes. Students were required to make detailed observations of phenotypes (e.g., health, movement, body shape, brood size). This gave students the opportunity to observe firsthand how a genetic mutation can affect the phenotype of an organism, and thus addressed our first learning outcome. Phenotypes exhibited by the deletion strains are listed in Table 1, and videos are available in the Supplemental Material.

\section{RNAi}

In the first $2 \mathrm{wk}$, students also used RNAi to deplete their gene of interest in C. elegans, with the goal of determining whether this yields the same phenotype as that of the genetic deletion. This part of the activity addressed our first and second learning objectives: to increase understanding of the relationship between genotype and phenotype and to increase understanding of RNAi and its utility. RNAi is a phenomenon in which duplexed RNA induces knockdown of gene function. This occurs by inhibited translation of the corresponding mRNA and sometimes also by silencing of genomic DNA (reviewed in Mello and Conte, 2004). A month before our first execution of this laboratory exercise, the Nobel Prize in Physiology or Medicine was awarded to Andy Fire and Craig Mello for their discovery of RNAi, which was accomplished in C. elegans. This added to student and instructor excitement for this part of the laboratory exercise.

In C. elegans, RNAi will occur if double-stranded RNA (dsRNA) is introduced into the animal (Fire et al., 1998; reviewed in Mello and Conte, 2004). Also, RNAi in C. elegans is systemic - meaning that the RNAi effect propagates throughout the animal even when the dsRNA is only introduced into some of the cells. Amazingly, a robust RNAi effect in C. elegans can often be achieved by feeding with bacteria that produce dsRNA corresponding to a gene of interest (Timmons and Fire, 1998; Timmons et al., 2001). This technique is referred to as feeding RNAi, and it is easy and inexpensive to perform.

In feeding RNAi, the HT115(DE3) strain of E. coli (henceforth referred to as "feeding RNAi bacteria") is used (Timmons et al., 2001). This strain of E. coli has the RNaseIII gene removed and replaced with a gene cassette containing T7 RNA polymerase driven by a lactose-inducible promoter (refer to Figure 1A). The feeding RNAi bacteria also contain a plasmid (L4440) with a cDNA corresponding to the target gene flanked by T7 RNA polymerase-binding sites (Timmons 


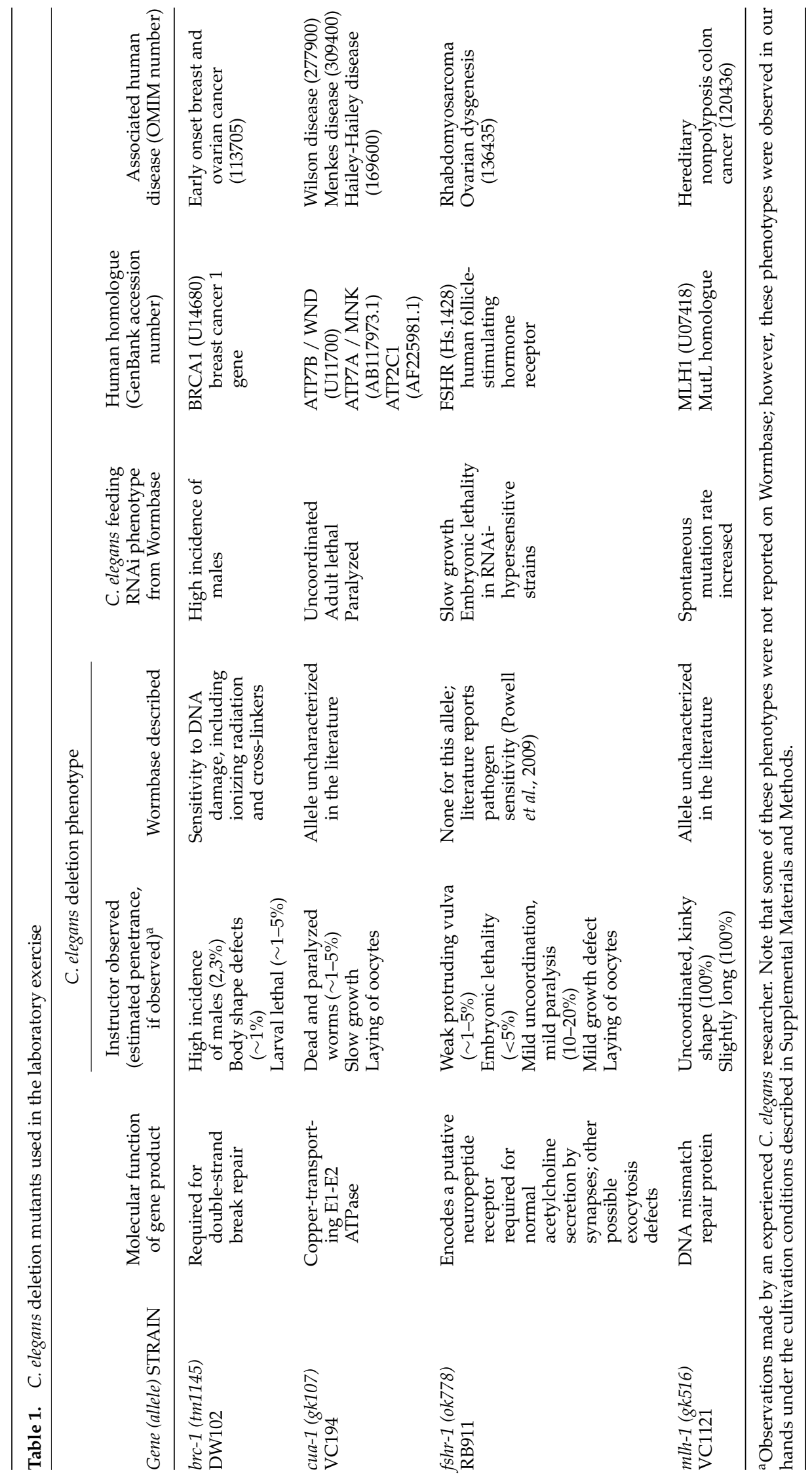



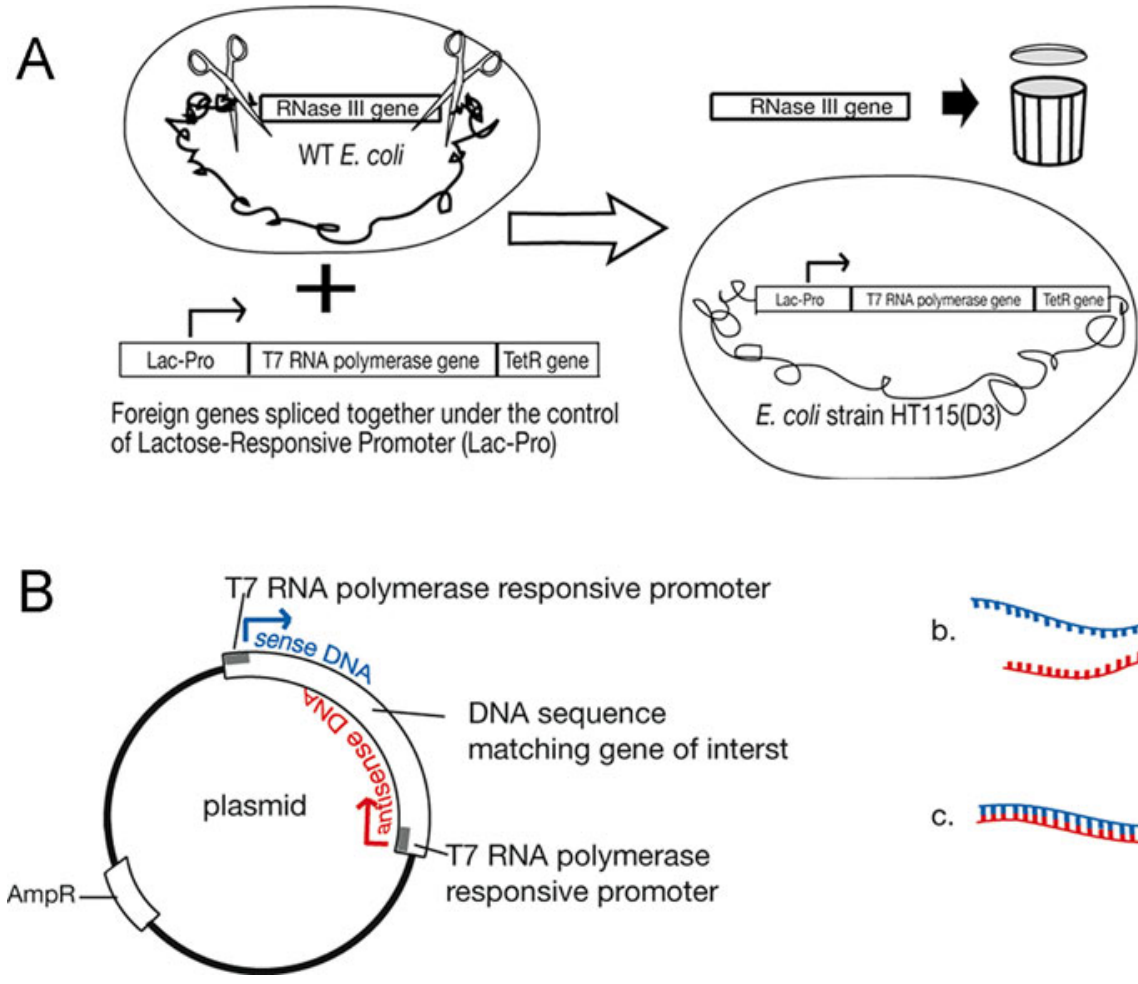

et al., 2001; refer also to Figure 1B). Thus, when the bacteria are exposed to lactose (or isopropyl $\beta$-D-1-thiogalactopyranoside [IPTG]), they will produce T7 RNA polymerase, which transcribes sense and antisense single-stranded RNA (ssRNA) from the cDNA. These ssRNA transcripts spontaneously anneal in the bacterial cells to generate dsRNA. When C. elegans feed on these bacteria, the dsRNA induces an RNAi response, knocking down the target gene's expression.

During the first week, an overview of the importance and general principles behind RNAi was given, and the technique of feeding RNAi was discussed; a prelab assignment on RNAi was due the following week. Prior to the first week's lab, the instructional staff inoculated and grew the bacterial cultures for the students. The students spread the bacteria on the feeding RNAi plates. Staff prepared a synchronized population of larval worms and subsequently added them to the students' feeding RNAi plates (refer to Supplemental Materials and Methods). This part of the laboratory exercise was the most intensive for the preparation staff. The worms were allowed to mature and lay eggs for $24 \mathrm{~h}$ and were then removed from the plates. One or two days later, during the second week, the students began observing the plates. By this point in time, the eggs on the control plates (which contained feeding RNAi bacteria with an "empty" feeding vector with no inserted cDNA) had hatched, and the worms were almost adults. This provided students with an appropriate control to which they could compare the worms treated with RNAi against their target gene. Students also performed observations later in the week during their lab session.

For their observations, students were supplied again with their deletion strains. One of their tasks was to determine whether feeding RNAi caused the same phenotype(s) as the genetic deletion. Later, when they had finished their bioinformatics analysis, they were able to formulate ideas as to
Figure 1. Diagrams to illustrate feeding RNAi used in the students' laboratory manual. (A) Generation of the $E$. coli HT115(DE3) strain used for feeding RNAi. This strain was made by excising the RNaseIII gene (encodes an enzyme that degrades dsRNA) and replacing it with a gene cassette containing the T7 RNA polymerase gene driven by a lactose-inducible promoter. This gene cassette also has a tetracycline resistance gene. (B) Plasmid used for feeding RNAi. This plasmid has a cDNA flanked by two T7 polymeraseresponsive promoters and carries an ampicillin resistance gene. When this plasmid is present in HT115(DE3) bacteria, and the bacteria are supplied with lactose (or IPTG), production of dsRNA is induced. The T7 RNA polymerase made by the HT115(DE3) bacteria binds to T7 RNA-responsive promoters both up and downstream of a cDNA inserted into the plasmid. This results in production of sense and antisense ssRNA. This complementary ssRNA spontaneously anneals to form dsRNA. When C. elegans eat bacteria expressing this dsRNA, an RNAi response can be induced in the worms.

why this was or was not the case. One of our goals was to help students appreciate that in some cases genetic mutations can yield phenotypes that differ from RNAi treatment. First, genetic mutations do not always result in a complete loss of function; some cause a partial loss of function or even a gain of function (for instance, some mutations make a protein constitutively active). Student comprehension of this promotes our first learning objective (increased understanding of the relationship between genotype and phenotype). Furthermore, RNAi does not usually result in a $100 \%$ knockout of gene expression, and some genes are more sensitive to RNAi than others; hence, RNAi is commonly referred to as a knockdown, versus a knockout, approach. Student comprehension of this promotes our second learning objective (increased understanding of RNAi and appreciation of its utility). For the genes used in this activity, the RNAi phenotypes were similar to, but usually milder than, the deletion strain phenotypes.

Of note, various RNAi hypersensitive strains could be used to customize this exercise to specific needs. For instance, there are RNAi hypersensitive strains, such as $r r f-3(p k 1426)$ and eri1(mg366), that generally allow stronger knockdown of genes in comparison with wild-type worms (Simmer et al., 2002; Kennedy et al., 2004). Also, some C. elegans cells, such as neurons, are resistant to RNAi. However, neuronal RNAi can be accomplished in a strain that ectopically expresses SID-1 in neurons (Calixto et al., 2010).

\section{Nested PCR to Detect Genetic Deletions}

In the second and third weeks, students performed nested polymerase chain reaction (PCR) to detect the assigned genetic deletion (refer to Supplemental Materials and Methods). By allowing students to visualize the genetic 
A

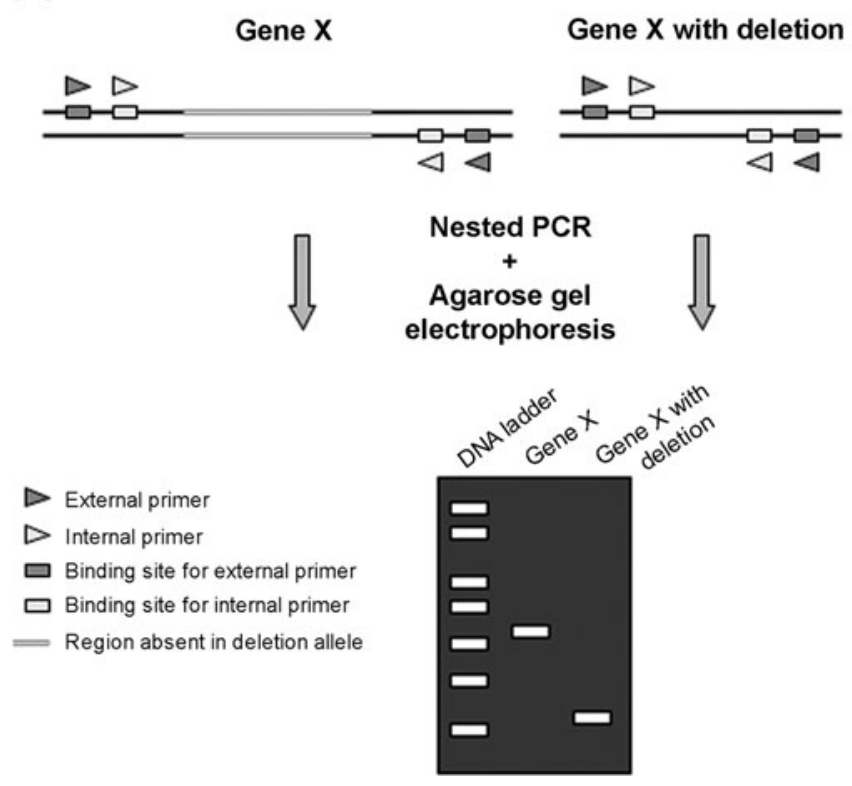

$B$

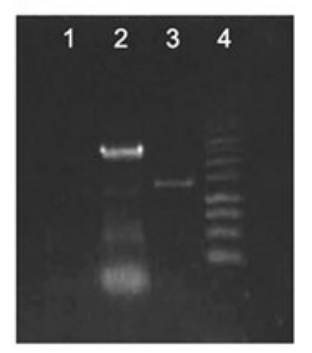

Figure 2. Diagram and example to illustrate nested PCR. (A) Schematic showing how nested PCR works. First, PCR is performed with the external primer set. The product of this reaction is used as a template for a second round of PCR using the internal primers. The size of the amplification product is determined by running the internal reaction on an agarose gel. If a deletion is present in the genomic region flanked by the primers, a smaller band is obtained. (B) Student gel demonstrating results from nested PCR. Lane 1: negative control, lacking template DNA; lane 2: genomic DNA from wild-type C. elegans; lane 3: genomic DNA from vha-12 mutants; and lane 4: DNA ladder. deletion in the worms that they had observed, this activity promoted our first learning outcome: to increase understanding of the relationship between genotype and phenotype. In nested PCR, two PCRs are performed: The first (external) reaction uses one set of primers, and the product is used as a template for a second reaction (internal), employing primers internal to the first set (Figure 2A). Being able to successfully select primers for this task required students to understand the process of PCR, how primers work, and the structure of DNA. For instance, students needed to understand that primers bind to a complementary DNA sequence and prime DNA synthesis of a second strand in the $5^{\prime}$ to $3^{\prime}$ direction. Student misconceptions about DNA replication and PCR have been well documented by others (Phillips et al., 2008; Robertson and Phillips, 2008), and this exercise provided an opportunity to increase understanding of these topics.

Students performed online tutorials to learn about PCR outside class time. During the second week, there was a prelab assignment on PCR and deletion screening. A class discussion of how PCR works and the technique of nested PCR was followed by an activity in which students were provided with sequence files for their assigned wild-type allele and corresponding deletion allele, and a worksheet that contained 10 potential primers (refer to Supplemental Material B for worksheets and Supplemental Material C for gene sequence files). They used Geneious DNA analysis software to determine the location of their deletion and to pick primers that would work for detecting it with nested PCR.

To confirm their deletion, students performed PCR on genomic DNA that they collected from C. elegans using the primers they selected. Students performed the external and internal reactions and ran the product from the internal reactions on an agarose gel. This was accompanied by a discussion and a worksheet on agarose gel electrophoresis (Supplemental Material D, based on Phillips et al., 2008).

\section{Bioinformatics Analysis}

In the third and fourth weeks, students used bioinformatics analysis to predict how the deletion in their gene would affect the mRNA and protein produced (refer to Supplemental Materials and Methods). This addressed and integrated our first and third learning objectives: to increase understanding of the relationship between genotype and phenotype and to build skills and confidence in using bioinformatics tools. Students worked in groups of two, using worksheets for guidance (Supplemental Material E). This was not intended to be a comprehensive experience in which students could independently explore bioinformatics tools on their own, but more of a guided tour of some of the most relevant tools available for analyzing their gene of interest. For the 2007 lab, the worksheet included introductory text, instructions, and questions to complete related to the databases and the Geneious software. For the 2008 lab, the worksheet was improved by including screen shots with embedded descriptions.

Students started by using a repository of information on the C. elegans genome (Wormbase) to explore available information on their gene, including a concise description, genetic position, gene expression patterns, available information on deletions and RNAi phenotypes, protein sequences, protein domains, and human orthologues. Though many students will not use Wormbase in the future, exploring it was an appropriate introduction to how data on model system databases are organized and accessed. Students also examined information available on the Online Mendelian Inheritance in Man (OMIM) database and used this to research human diseases that result from mutations in orthologues of their assigned genes. Human diseases fascinate most biology students, and we wanted to make sure they were introduced to how studying a gene in a worm might allow us to figure out something about human biology.

The worksheet then guided students in the use of Geneious for annotating the structure of their assigned gene; annotations included introns, exons, untranslated regions, 
and the position of the deletion in the mutant allele. Using Geneious, students also translated the mRNA of their gene of interest and attempted to determine how their assigned deletion might affect the protein sequence. Some students quickly discovered faster ways to complete the annotations than the methods described in the worksheet. Students used the SMART website to identify protein motifs present in their protein. Additionally, students in the 2007 lab were required to explore the protein structure of the assigned gene using Jmol. This was optional in the $2008 \mathrm{lab}$, because students found the 2007 worksheet to be too long, and we felt that focusing on the other tasks was more important. Jmol was used earlier in the semester during a different lab activity, so nearly all students were familiar with it before this lab began.

This activity was intended to help students grasp the relationships among DNA, RNA, and protein, and to give students a chance to think more deeply about DNA structure. For instance, some deletions (such as the one present in $\mathrm{mlh}$ $1(g k 516))$ remove the promoter and start codon of the transcript, and students were able to predict that this would result in no mRNA or protein being made. In other cases, deletions alter the reading frame, for instance $f s h r-1($ ok778) has a 3224 base-pair deletion and 393 base-pair insertion that results in a shifted reading frame and premature stop codon. Some deletions do not affect the reading frame but would still be predicted to yield a shorter mRNA and/or protein (e.g., brc1(tm1145), which has a 669-base pair deletion).

We also wanted to emphasize the relationship between DNA structure and protein function. An important question aimed at enabling this was question 33 on the worksheet: "From the annotated protein and knowing the location of your deletion, what protein domains are affected by the deletion? How might the deletion of these/this domain(s) affect the function of your protein?" We hoped this question would stimulate students' critical thinking and discussion about how DNA mutations can affect protein function and the organism's phenotype.

\section{Preparation of Scientific Posters}

As a capstone activity, students prepared scientific posters (instructions in Supplemental Material F). Students were asked to present their data, to explain how their assigned genetic deletion and RNAi treatment may have induced the observed phenotypes (based on what is known about the molecular function of the gene), and to use this and other sources of information to evaluate whether C. elegans is a useful model system for studying their human disease gene of interest. Students were also asked to provide future research directions. During this stage, discussions were held to help students form criteria for evaluating whether C. elegans is a useful model system for studying their assigned genes.

Although we discussed how model organisms are used to study human disease and helped students form criteria that could be used to assess the usefulness of a model system in this regard, we did not explicitly make connections for the students between the genes they were studying in C. elegans and human disease genes. Rather, we left it to the students to make such discoveries in their research (we did show students how to find articles on PubMed and how to research their human disease using OMIM). This provided students an important chance to venture into the scientific literature and to formulate their own conclusions about whether there were enough similarities in gene structure, function, and phenotype to make C. elegans a useful model system for studying their assigned human disease genes.

The poster assignment provided an opportunity for students to synthesize what they had learned and develop their problem-solving skills. The poster assignment therefore supported our fifth learning outcome: integration of the concepts, skills, and knowledge acquired in this module. Examples of student posters are included in Supplemental Material G. The rubric that was used to evaluate student posters is described in the Materials and Methods section and is included in Supplemental Material $\mathrm{H}$.

\section{LABORATORY ACTIVITY SCHEDULE}

Biocore 304 met twice a week, for a 50-min session typically devoted to discussion and for a 3-h session focused on laboratory activities (discussion sections met 1-2 d prior to lab). The following is an overview of the tasks accomplished for each class meeting time during the 2008 semester. Additionally, the 2008 lab manual is available in Supplemental Material A. In 2007, the lab exercise was similar, except the order of the PCR and RNAi experiments was reversed; also, a PCR/bioinformatics prelab assignment was used instead of a PCR/deletion screening prelab. The 2007 lab manual is available upon request. All assignments, worksheets, and rubrics used in 2008 are available in Supplemental Material B-H.

Week 1 Discussion: Overview of Laboratory Exercise and Observation of C. elegans

(a) Discuss utility of C. elegans as a model system and provide overview of laboratory exercise.

(b) Observe wild-type C. elegans and assigned C. elegans deletion strain.

\section{Week 1 Lab: Discuss and Begin RNAi Experiment}

(a) Discuss RNAi and how it works.

(b) Seed bacteria onto plates for feeding RNAi experiment.

(c) Repeat observations of wild-type C. elegans and assigned C. elegans deletion strain.

Week 2 Discussion: Observe and Characterize Phenotypes Induced by RNAi

(a) RNAi prelab due.

(b) Repeat observations of wild-type C. elegans and assigned C. elegans deletion strain.

(c) Observe and document phenotypes induced by RNAi.

(d) Read "Super Models" article (Barr, 2003), which discusses the utility of model organisms.

Week 2 Lab: Finish RNAi Experiment and Begin PCR to Detect Deletion in Gene of Interest

(a) PCR/deletion screening prelab due.

(b) Discuss model systems.

(c) Continue observations of feeding RNAi experiment.

(d) Isolate DNA from C. elegans (wild-type and deletion strain).

(e) Discuss how PCR works and how to select primers. 
(f) Use sequence analysis software to determine where the deletion occurs in the gene of interest.

(g) Use PCR worksheet to select primers.

Week 3 Discussion: External Nested PCRs and Model Systems

(a) Class discussion of which primers will and will not work.

(b) Perform external PCRs on worm lysates from week 2.

(c) Continue discussing model systems.

(d) Discuss poster assignment and expectations.

Week 3 Lab: Internal Nested PCRs and Beginning of Bioinformatics Analysis

(a) Perform internal reactions for nested PCR.

(b) Discuss bioinformatics and begin bioinformatics analysis using worksheet.

Week 4 Discussion: Bioinformatics Analysis and Posters

(a) Continue bioinformatics analysis.

(b) Work on posters (draft due in lab).

Week 4 Lab: Analysis of Results from PCR Experiment and Peer Review of Poster

(a) Analyze internal PCRs by agarose gel electrophoresis.

(b) Complete gel electrophoresis worksheet.

(c) Peer review of poster draft.

Week 5 Lab: Final Poster Assignment Due

\section{MATERIALS AND METHODS}

\section{Genes of Interest}

We chose C. elegans genes orthologous to human disease genes (Culetto and Sattelle, 2000) that met these criteria: 1) feeding RNAi was reported to yield a visible phenotype; 2 ) a viable homozygous deletion strain was available that had a visible postembryonic mutant phenotype(s); and 3) the deletion was large enough to be easily detected ( $>700$ base pairs) but not more than 3000 base pairs in size. Five genes fit these criteria, and each group of students was assigned one of these genes to work with for this project. Table 1 shows the four genes studied in 2007 and 2008, along with the C. elegans strain that carries the mutation. The vha-12 gene was used in 2007, but was not assigned in 2008 , as it had a very mild deletion phenotype.

\section{Assessment}

Pre-and Postsurveys. One way we gathered information on student learning was by administering pre- and postsurveys, which were completed anonymously online. The presurvey was submitted 3-5 d before the start of the first day of the exercise, and the postsurvey was submitted 2-3 wk after the poster assignment was due. All surveys were nearly identical (2007 presurvey is included in Supplemental Material I). To encourage a high response rate, students were given two bonus points for completing the surveys. In 2007, 109 students were enrolled in the course; 103 students completed the presurvey, and all students completed the postsurvey. In 2008, 116 students were enrolled in the course; all students completed the presurvey and 112 completed the postsurvey.
The surveys allowed assessment of perceived and actual student learning gains. We gauged perceived gains in: 1) content knowledge and 2) confidence with skills. To assess perceived gains in content knowledge, we asked such questions as: "How well do you understand DNA replication?," with a scale of five choices provided (refer to Figure 3). To assess student confidence with skills, we asked students to perform tasks like: "Choose the statement that best reflects your confidence in using Wormbase," with a scale of four choices provided (refer to Figure 5). Since these surveys assessed students' perceptions of how well they knew a topic or how comfortable they were with a skill, they were an indirect measure of student learning. Actual increases in students' content knowledge were assessed by some of the survey questions. For instance, to gauge student knowledge before and after the activity, we posed questions such as: "How does RNAi work? Circle your choice below" (refer to Figure 4). The responses to most questions on the pre- and postsurveys in 2007 and 2008 were very similar between the two years. For this reason, we show combined data in the figures, except in cases in which there were significant differences.

Additionally, on the postsurveys, we used responses to the question "Do you have any additional comments?" to gather student feedback on the laboratory exercise. This did not assess learning gains per se, but gave us valuable feedback on what students liked and disliked about the exercise.

Poster Rubric. The most powerful approach we used to assess student learning was examining content in the posters. This was done by directly observing and analyzing the students' work and by using a detailed rubric to assign a letter grade (Supplemental Material H). This allowed us to gauge actual learning gains versus the perceived learning gains that were primarily assessed in the surveys. We would like to note that, for grading, students were evaluated on the quality of their data presentation, interpretation, and strength of reasoning, and not on whether they felt $C$. elegans was a good model system or not for studying their assigned gene. The following nine categories were evaluated on a scale of $0-4$ $(0=$ inadequate, $1=$ adequate, $2=$ good, $3=$ very good, 4 = excellent): Title; Abstract; Introduction; Materials and Methods; Results; Discussion; Visuals; Literature Cited; and Overall Grammar, Organization, and Wording. Descriptions of how the number grades (0-4) were assigned for each category is explained in the rubric (Supplemental Material H). For instance, the description for earning a " 4 " for Results is: "Uses very concise text to refer to figures/graphs that highlight the following evidence: deletion mutant phenotype and genotype, bioinformatics analysis of genetic deletion and its effects on mRNA and protein, and RNAi phenotypes. If you had problems collecting valid data, state what the problems were that make your data invalid." The rubric also describes how letter grades were assigned. For instance, to earn an " $\mathrm{A}$ " letter grade, the poster had to earn a " 4 " in Introduction, Materials and Methods, Results, Discussion, and Visuals; and at least a " 3 " in the other categories.

\section{Demographics of the Student Population}

For the 2008 cohort, there were 53 females (45.7\%) and 63 males $(54.3 \%)$. At the time of the exercise, $98 \%$ were sophomores and $2 \%$ were juniors. The average first-semester GPA 

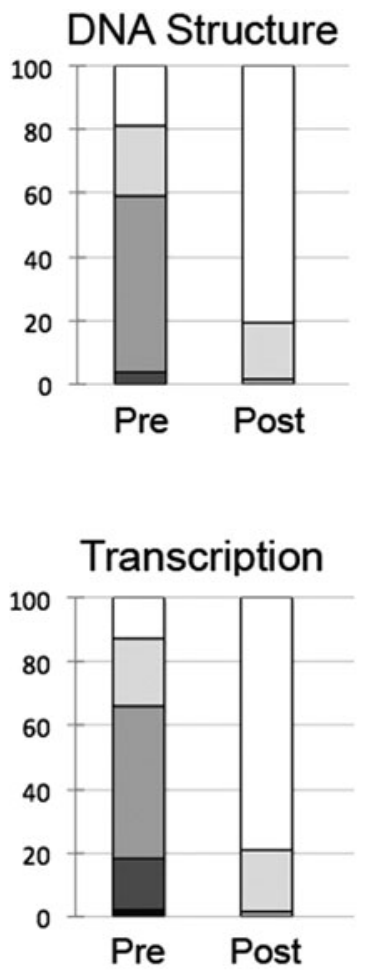

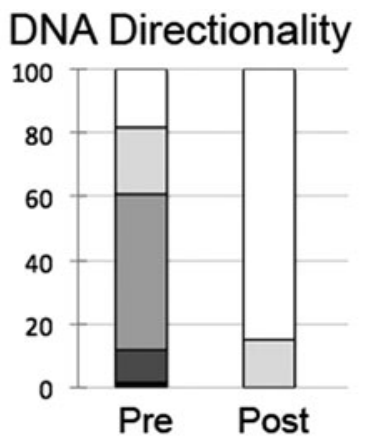

\section{Translation}

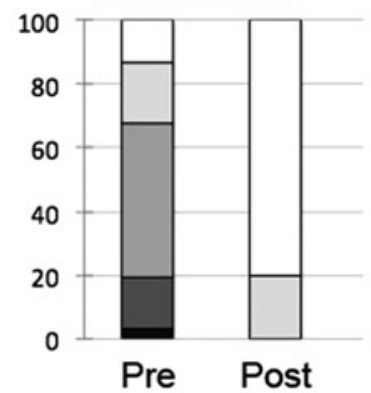

Gene Structure

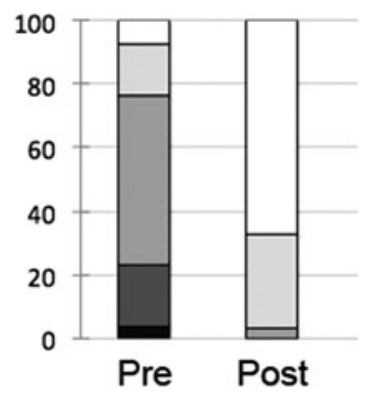

Genotype v. Phenotype

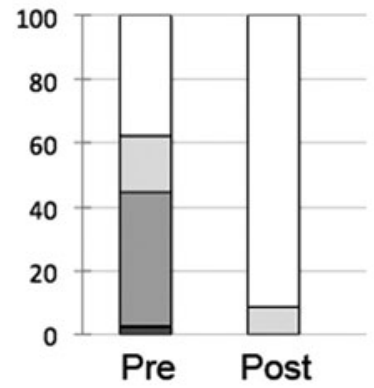

DNA Replication

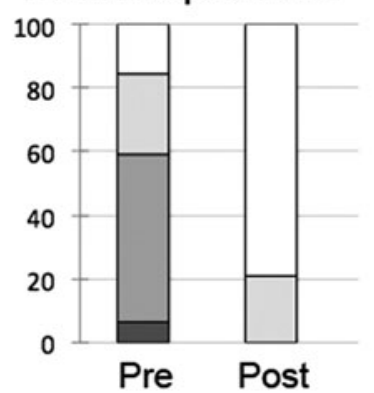

\section{How Genetic Mutations Cause Disease}

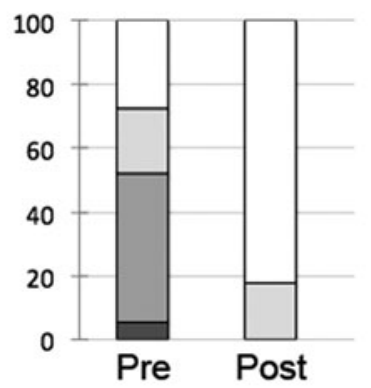

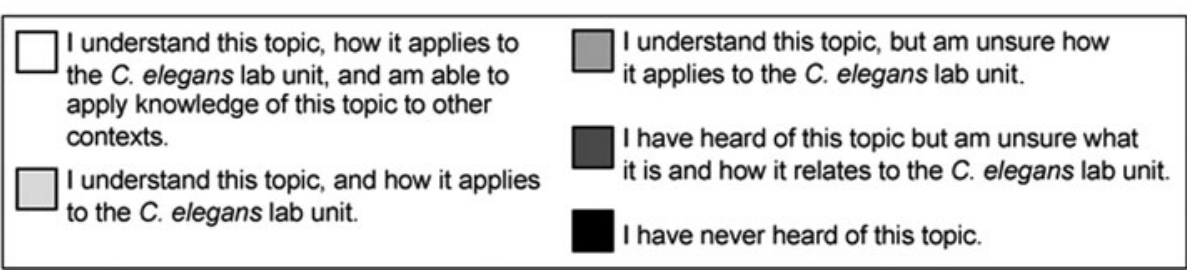

Figure 3. Student self-reports on understanding of the relationship between genotype and phenotype and associated topics. Students were asked to rate their understanding of these topics using the given scale. Bar graphs show the percentage of students (out of a total of $100 \%$ ) that chose the indicated responses on pre- and postsurveys. The data for 2007 and 2008 were very similar and were therefore combined (presurvey: $n=219$; postsurvey: $n=221$ ).

for these students (reported in their Biocore applications) was 3.57 out of 4 . This typically includes the first semester of inorganic chemistry (Biocore 304), first semester of calculus, and additional breadth requirement courses.

\section{RESULTS}

\section{Increasing Student Understanding of the Relationship between Genotype and Phenotype}

One goal of this exercise was to enrich student understanding of how genetic mutations can lead to changes in the protein produced by a gene, which can subsequently affect the phenotype of the organism. Aspects of the laboratory exercise that most specifically addressed this learning outcome were: 1) observing wild-type C. elegans and worms carrying a deletion in the assigned gene; 2) performing nested PCR to detect the assigned deletion; and 3) using bioinformatics analysis to determine how the genetic deletion would affect the protein made from the gene. More specific comments on the bioinformatics analysis are provided in Helping Students Increase Skills and Confidence in Use of Bioinformatics Tools.
In terms of physically performing this work, students were largely successful in using stereomicroscopes to observe C. elegans, although they found this to be challenging. More comments on this are included in the Discussion. For the nested PCR activity, all groups successfully chose appropriate nested primers from the list of 10 available, although some required hints from the instructors to get the correct solution. If the laboratory had smaller enrollment, it might have been possible to have students design their own primers, but the approach used at least allowed students to go through the process of selecting appropriate primers to use. As an added benefit, prior to running the activity, we were able to test the primer sets and optimize the conditions and therefore were confident the primers would work. Most groups successfully performed nested PCR (a sample student gel is shown in Figure 1B). Successful use of PCR to detect deletions in the $C$. elegans genome was also shown by Lissemore et al. (2005) in an intermediate-level undergraduate molecular biology course.

We performed pre- and postsurveys to determine students' self-reported perceptions of how well they understood genotype versus phenotype and how genetic mutations cause disease, as well as other topics related to this learning 


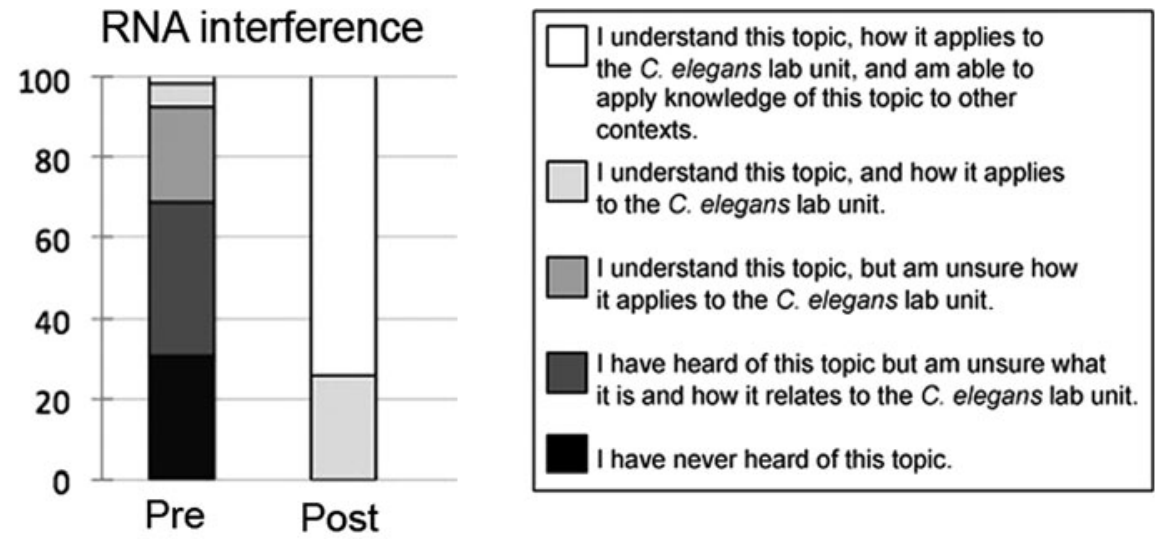

\begin{tabular}{|l|c|c|c|}
\hline $\begin{array}{c}\text { How does RNAi work? } \\
\text { Select all that apply. }\end{array}$ & $\begin{array}{c}\text { Knocks down gene } \\
\text { function by causing } \\
\text { mRNA degradation. }\end{array}$ & $\begin{array}{c}\text { Knocks down } \\
\text { gene function by } \\
\text { causing DNA } \\
\text { degradation. }\end{array}$ & $\begin{array}{c}\text { Knocks down } \\
\text { gene function by } \\
\text { destroying } \\
\text { ribosomes. }\end{array}$ \\
\hline Pre-survey & $77 \%$ & $20 \%$ & $22 \%$ \\
\hline Post-survey & $98 \%$ & $17 \%$ & $2 \%$ \\
\hline
\end{tabular}

Figure 4. Student self-reports of understanding, and student knowledge of RNAi. Bar graphs show the percentage of students (out of $100 \%$ ) who chose the indicated responses on pre- and postsurveys. The data for 2007 and 2008 were very similar and were therefore combined (presurvey: $n=219$; postsurvey: $n=221$ ).

outcome, including: DNA structure, DNA directionality, gene structure, DNA replication, transcription, and translation (Figure 3). In presurveys, the majority of students reported that they understood these topics, but were not confident in their ability to apply this knowledge. After the lab exercise, the majority of students (67-91\%, depending on the topic) felt they could apply knowledge of these topics in other contexts. After the activity, students were least confident about gene structure $(67 \%$ were confident in their ability to apply knowledge on this topic); however, this was improved greatly from the presurvey level of $8 \%$. Importantly, students were most comfortable with understanding genotype versus phenotype (in postsurveys, $91 \%$ were confident in their ability to apply knowledge on this topic; presurvey level was 38\%). Thus, the data suggest that the activity effectively promoted our first learning objective (to increasing student understanding of the relationship between genotype and phenotype). An important note is that the survey questions described above assessed students' perceived, versus actual, increase in understanding these topics. Comments on this and suggestions for improvements to the assessment are included in the Discussion.

\section{Increasing Student Understanding of RNAi and Appreciation of Its Utility}

Our second major goal involved promoting student knowledge and appreciation of RNAi. Despite its importance in gene regulation and as an experimental tool, textbook coverage and undergraduate laboratory exercises available for RNAi are not very plentiful. However, a few published studies in education journals discuss instructional success apply- ing RNAi in C. elegans (Andersen et al, 2008; Hurd, 2008; Miller et al., 2009).

Our results indicate that students did not know very much about RNAi before performing this laboratory module (Figure 4), and there was a large leap in their understanding after completing the exercise. For example, in the presurveys, $27 \%$ of students indicated that they were "somewhat confident" and 7\% indicated that they were "very confident" in their ability to explain the general mechanism of how RNAi works. By the end of the exercise, $73 \%$ indicated that they were "very confident" in their ability to do so. In addition to students perceiving that they understood RNAi better, they also demonstrated actual learning gains with improved performance selecting the correct answer to the multiple-choice question: "How does RNAi work?" (Figure 4). Our personal observations indicate that students enjoyed learning about this phenomenon, because of its newness and promise. For instance, one student remarked in the postsurvey that, "It was a very interesting lab because so much is still unknown about the potential for RNAi."

\section{Helping Students Increase Skills and Confidence in Use of Bioinformatics Tools}

Our third learning outcome was for students to increase confidence and skills in using bioinformatics tools. The bioinformatics exercise also helped students achieve our first learning outcome (to increase understanding of the relationship between genotype and phenotype) by providing an opportunity for students to annotate genes and explore changes in structure resulting from a deletion mutation. They could then use this information to enhance their understanding of the molecular basis of the phenotype(s) they 


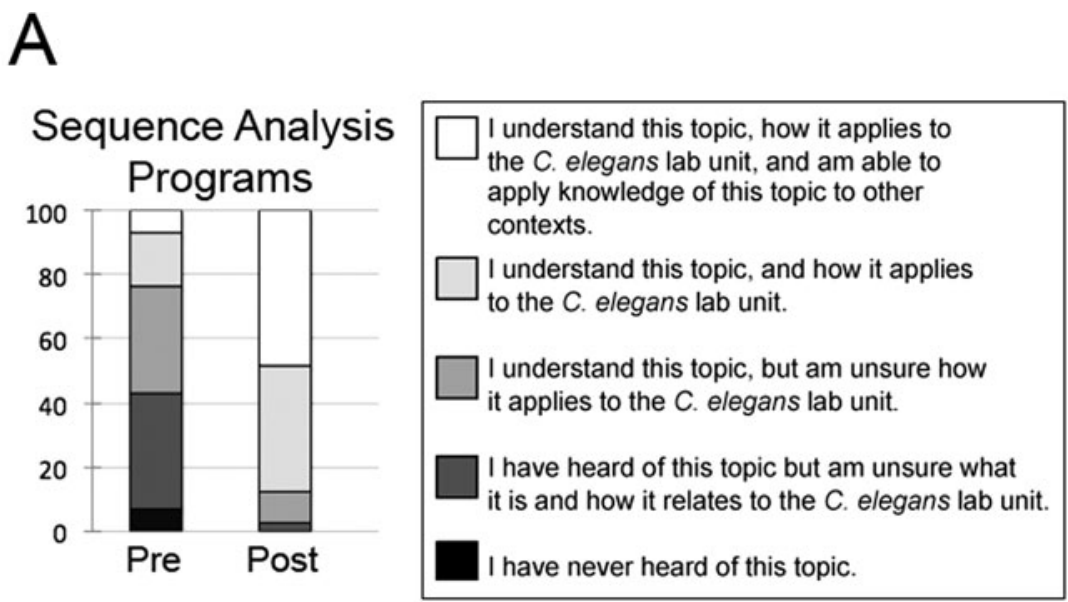

B
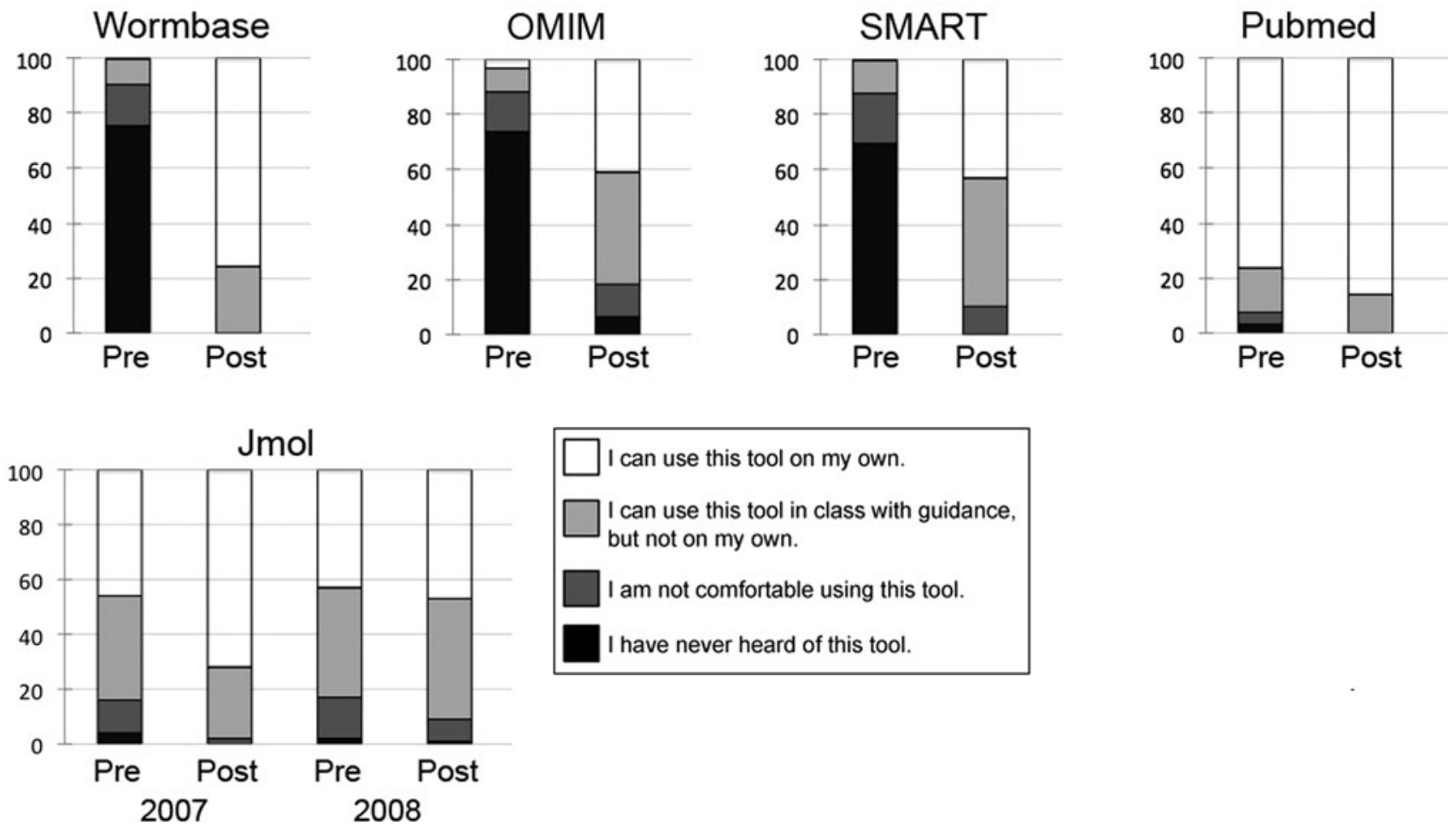

Figure 5. Student self-reports on understanding bioinformatics. (A) Students were asked to rate their understanding of sequence analysis programs (BLAST and Geneious), using the given scale. (B) Students were asked to choose the statement that best reflected their confidence in using the indicated bioinformatics tools. For (A) and (B), bar graphs show the percentage of students (out of 100\%) who chose the indicated responses on pre- and postsurveys. For all categories in (A) and (B) except Jmol, data for 2007 and 2008 were very similar and were therefore combined (presurvey: $n=219$; postsurvey: $n=221$ ). For Jmol: $n$ values were 103 students for the 2007 presurvey, 109 students for the 2007 postsurvey, 116 students for the 2008 presurvey, and 112 for the 2008 postsurvey.

had observed. Bioinformatics analysis of genes and their encoded proteins has also been used successfully in other undergraduate laboratory courses (Griffin et al., 2003; Honts, 2003; Almeida et al., 2004; Brame et al., 2008). Our approach was unique in that it involved an integrative approach that coupled bioinformatics analysis to detection of genetic deletions with nested PCR and exercises that explored the relationship between genotype and phenotype. This promoted our fifth learning objective: integration of the concepts, skills, and knowledge acquired in this module.
Several challenges exist in teaching bioinformatics. One obvious one is that the tools and databases change rapidly, so a detailed guide designed for students quickly becomes outdated. Another challenge is variation in student confidence and abilities with new websites and software. Some students are much more comfortable with computers and less easily frustrated, and thus are better explorers of new tools. Accordingly, some students stated in postsurveys that they found the bioinformatics worksheets to be too directive, while others wanted to spend 
more time going through the bioinformatics tools with an instructor.

After this activity, students reported large perceived gains in confidence using bioinformatics tools (Figure 5). For instance, $76 \%$ reported in postsurveys that they could use Wormbase on their own (increased from $0.5 \%$ in presurveys). Additionally, most students had never heard of OMIM before this lab, but became comfortable with it after this exercise (in postsurveys, $82 \%$ reported that they could use this tool on their own or with some guidance). Students also reported strong increases in their confidence in using the alignment tools, Geneious and BLAST. When asked how they felt about these sequence-alignment programs, $23 \%$ of students indicated in presurveys that they understood these programs and how the programs related to the C. elegans lab unit. In postsurveys, this had increased dramatically to $88 \%$. Additionally, most students had not heard of SMART before this exercise, but after being introduced to this resource, students were comfortable using it. In postsurveys, $43 \%$ of students reported they felt comfortable using this tool on their own, and another $47 \%$ reported they felt they could use this tool with guidance. For their poster assignments, students did background research on PubMed. Their confidence in using PubMed was initially high and increased slightly during the lab exercise (Figure 5).

The 2007 cohort became much more comfortable with Jmol as a result of this activity (as mentioned above, Jmol was not included in the 2008 activity). Those reporting that they could use Jmol on their own increased from $46 \%$ (presurvey 2007) to $72 \%$ (postsurvey 2007). A benefit of including Jmol in the lab is that some students were able to relate the threedimensional protein structure to the effect that a deletion may have on protein function.

Successful completion of the bioinformatics worksheet, incorporation of this data into the poster assignments, and students' self-reported gains all indicate that this part of the activity was successful in promoting our third learning outcome: increased confidence and skills in using bioinformatics tools. Also of note, although not all students were enthusiastic about learning bioinformatics tools, some students reported in the postsurvey that they were very excited to learn these tools, in part because they saw themselves as likely to use them in the future.

\section{Increasing Student Appreciation for the Utility of Model Organisms}

Helping students gain an appreciation for the utility of model organisms in biology was another major goal of this laboratory exercise. Many nonbiologists and biology students early in their training do not appreciate the utility of using model organisms. This appreciation is crucial, because model organisms have many genes and proteins that are homologous to human genes and so provide fertile ground for understanding conserved signaling pathways and processes (Fields and Johnston, 2005).

Survey results indicate that students exhibited an increased appreciation for the utility of model organisms as a result of this activity (Figure 6). In the presurveys, 52\% of students indicated they understood the use of model organisms in disease research and were able to apply this idea. By the end of the exercise, this increased to $97 \%$. Indeed, one of the most

\section{Use of model organisms in human disease research}
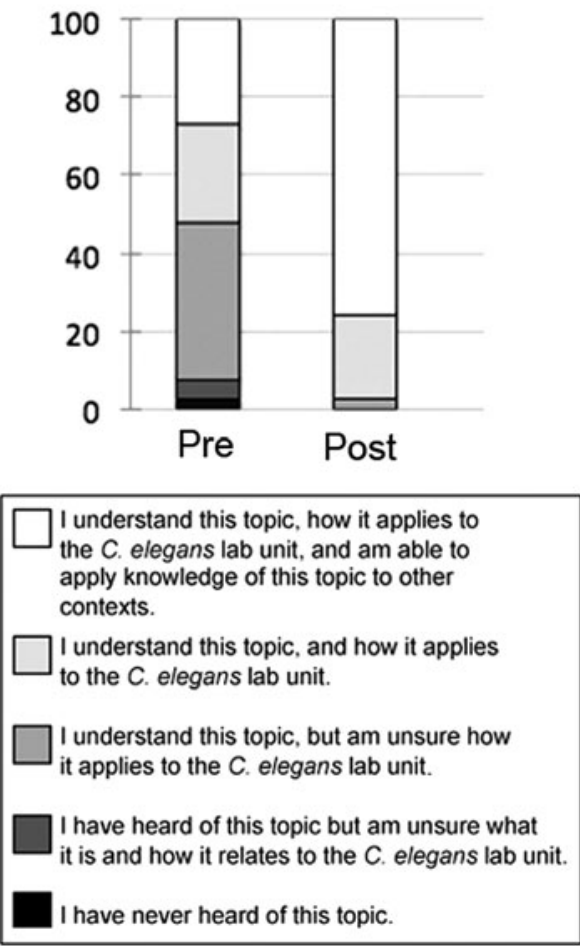

Figure 6. Student self-reports on understanding the utility of model organisms. Students were asked to rate their understanding of the use of model organisms in human disease research using the given scale. Bar graphs show the percentage of students (out of 100\%) who chose the indicated responses on pre- and postsurveys. The data for 2007 and 2008 were very similar and were therefore combined (presurvey: $n=219$; postsurvey: $n=221$ ).

exciting moments of this lab for the instructors was when a lab group related the egg-laying defect in $b r c-1$ mutant worms to the role of its orthologue (brca-1) in human ovarian cancer. Additionally, one student remarked in the postsurvey that, "It was a good exercise to really understand model systems and realize how important they are in experiments and modern medicine." Despite this, there were some students who struggled with this concept, and there are more comments on this in the Discussion.

\section{Integration of the Concepts, Skills, and Knowledge Acquired in This Module}

Our overarching learning outcome was for students to integrate the concepts, skills, and knowledge acquired throughout the laboratory unit. This was important for several reasons. First, requiring students to integrate information from various sources allowed the students to experience how the scientific process works. Second, integrating what they learned from their phenotypic observations, bioinformatics analysis, and outside research provided students a chance to develop their critical thinking skills. Finally, the unit allowed students to develop a deeper understanding of how altering the genetics of an organism can lead to disease. This learning outcome was promoted throughout the unit by 


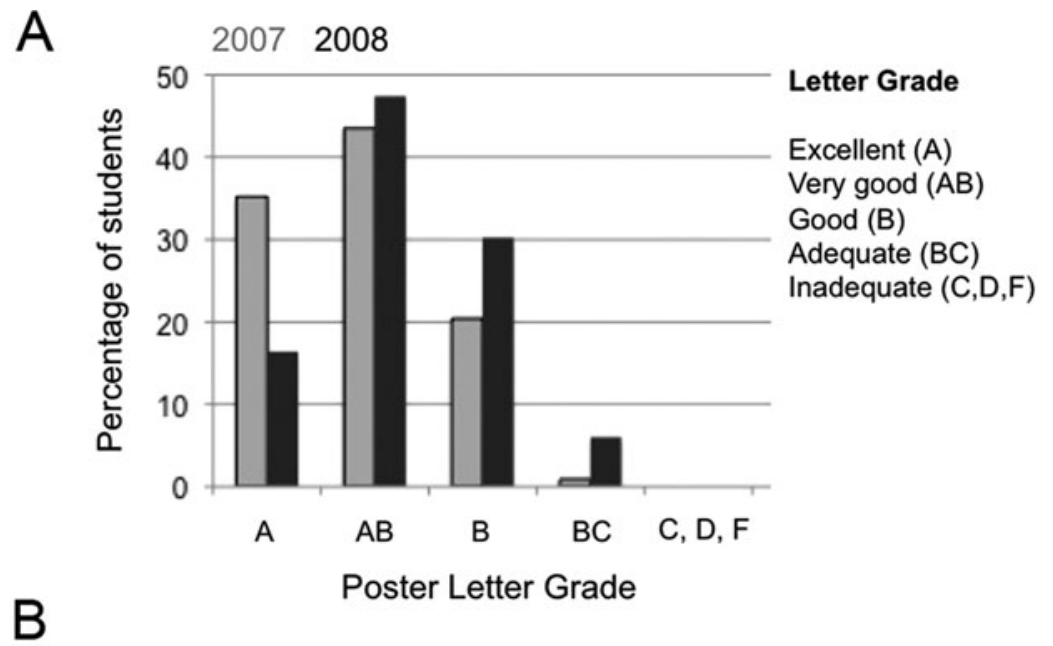

\begin{tabular}{|l|l|}
\hline $\begin{array}{l}\text { Letter } \\
\text { Grade }\end{array}$ & Minimum Criteria \\
\hline A & $\begin{array}{l}\text { Earned a "4" in Introduction, Materials and Methods, Results, Discussion, and Visuals. } \\
\text { Earned a "3" or better in Title, Abstract, Literature Cited, and Overall Grammar, } \\
\text { Organization and Wording. }\end{array}$ \\
\hline AB & $\begin{array}{l}\text { Did not meet criteria for an "A", but earned a "3" in Introduction, Materials and Methods, } \\
\text { Results, Discussion, and Visuals; and a "2" or better in Title, Abstract, Literature Cited, and } \\
\text { Overall Grammar, Organization and Wording. }\end{array}$ \\
\hline B & $\begin{array}{l}\text { Did not meet criteria for an "AB", but earned a "2" in Introduction, Materials and Methods, } \\
\text { Results, Discussion, and Visuals. Earned a "1" or better in Title, Abstract Literature Cited, } \\
\text { and Overall Grammar, Organization and Wording. }\end{array}$ \\
\hline BC & Did not meet criteria for a "B", but earned a "1" or better in all sections. \\
\hline
\end{tabular}

4 = excellent; 3 = very good; 2 = good; 1 = adequate; 0 = inadequate

Criteria for "C", "D", and "F" are described in Supplemental Material H.

Figure 7. Grades earned on the scientific poster. (A) Graph showing percentage of students earning the indicated letter grades in 2007 $(n=109)$ and $2008(n=116)$. Note that students worked collaboratively on posters in 2007, while posters were done individually in 2008. (B) Chart indicating how letter grades were assigned. Supplemental Material H contains a detailed rubric (including how numerical scores were determined for all categories); samples of student posters are included in Supplemental Material G.

discussion, by the bioinformatics exercise (discussed above), and by a capstone project, in which the students designed scientific posters to present their data and conclusions. Unfortunately, due to time constraints, students did not do oral presentations of their posters. This would have added to the richness of the learning experience; however, student feedback in postsurveys indicated that students benefited from the significant intellectual work involved in synthesizing their data and designing the poster. One student remarked in the postsurvey that: "The poster assignment was difficult but helpful."

In addition to providing a time for reflection and integration, the poster assignment also gave students an opportunity to become more comfortable and proficient at presenting data and conclusions in the form of a scientific poster. Encouragingly, in both semesters, students exhibited a gain in confidence in preparing posters in scientific format. In presurveys, $63 \%$ (2007) and 37\% (2008) were "very confident" in their ability to do this task, and in postsurveys this increased to $79 \%$ (2007) and 63\% (2008). Also of note: The students prepared posters in groups in 2007, while posters were done as an individual assignment in 2008. The sentiment "I thought that the posters should have been more of a group effort," was echoed by several students in the 2008 postsurveys, and we agree that having the students work in groups seemed to be more enjoyable and effective.

We performed analysis to determine the spread of letter grades ("A" / " $\mathrm{AB}^{\prime \prime} /$ "B" / "BC" / " $\mathrm{C}^{\prime \prime} /$ " $\mathrm{D}$ " / " $\mathrm{F}$ ") for the poster assignment (Figure 7A). A brief description of how letter grades were assigned is included in Figure 7B, and a detailed rubric is available in Supplemental Material H. In 2007, 35\% of posters earned an "A," whereas this dropped to $19 \%$ in 2008. This decrease may have been due to the poster being an individual assignment, rather than a group assignment that year. The percentage of posters earning an " $\mathrm{A}$ " or " $\mathrm{AB}$ " was $89 \%$ in 2007 and $74 \%$ in 2008. In both years, no posters were scored as having a grade lower than a "BC." This indicates that the majority of students in both 2007 and 2008 succeeded in performing well on the poster assignment. The reason why there were no grades below a "BC" may stem in part from the rubric, which makes it difficult to assign a lower grade; however, we also believe that it reflects the highly motivated nature of this student population.

We also performed analysis on the content of the 116 posters from 2008. In these posters, $75 \%$ of students indicated that $C$. elegans would be a good model system for studying the basic biology of their assigned human disease gene. Some of the common reasons given for this conclusion were 
the following: C. elegans are easy to manipulate; C. elegans with the assigned genetic deletion have visible and reproducible phenotypes; and there is significant homology between the assigned gene in worms and humans. This decision was strongly influenced by the identity of the assigned gene. Of students working with $m l h-1,100 \%$ stated that $C$. elegans is a good model system for studying this gene. For the other genes, the percentages were: $89.5 \%$ (cua-1), $65.7 \%$ (brc-1), and $35 \%\left(f_{s h} r-1\right)$. The main reasons for stating that C. elegans is not a good model system for investigating $f$ sh $r-1$ function was the weakness of the mutant phenotype. Conversely, $m l h-1$ has the strongest mutant phenotype of the genes used in this exercise, which added to its appeal.

We also asked students to propose future directions. For the most part, these were feasible and at times quite sophisticated and creative for second-year undergraduates. Some students suggested more detailed analysis of the role of their assigned gene in particular organ systems. For instance, one group working on cua-1 was interested in looking specifically at how the deletion allele affects the nervous system, which they felt would help them to understand the why paralysis results in Wilson disease. Other groups working with cua-1 were interested in determining the copper levels in the cells of worms with the deletion allele, since the protein encoded by the cua-1 gene is a copper transporter. Some groups wanted to home in on the function of specific structural domains. For instance, a group working on $b r c-1$ proposed determining the functions of the conserved RING and BRCT domains. Additionally, several students proposed determining whether the human version of the gene could rescue the mutant phenotype of the C. elegans deletion strain. Overall, our analysis of students' posters indicated that the task required students to integrate information from various channels to arrive at a conclusion concerning the question at hand and prompted many students to formulate plausible future directions.

\section{DISCUSSION}

The described laboratory exercise provided undergraduate students with a significant learning experience in molecular genetics and the scientific process. Students were assigned a gene in C. elegans orthologous to a human disease gene and were then guided through a series of experiments and analyses that allowed them to arrive at an answer to the question: Is C. elegans a good model system for studying the function of your assigned human disease gene? The five major learning objectives for this exercise were: 1) increased understanding of the relationship between genotype and phenotype, 2) increased understanding of RNAi and appreciation of its utility, 3) increased skills and confidence in using bioinformatics tools, 4) deeper appreciation for the importance of model organisms, and 5) integration of the concepts, skills, and knowledge explored in this module. As documented above, survey results, student comments, and performance on the poster assignment strongly suggest success in attaining the stated learning objectives. Interestingly, students reported the most dramatic gains in understanding of and confidence in using bioinformatics tools (specifically Wormbase, OMIM, and SMART) and in understanding RNAi. A possible explanation for this is that these were new topics for the students, so these were areas in which the most could be gained.
The strongest evidence for the success of this exercise was derived from student performance on the posters. The poster grades and direct analysis of the posters indicated the majority of students were able to successfully present and analyze their data and to formulate logical responses to the question at hand. Furthermore, as stated above, we were quite impressed with the future research directions that some of the students proposed.

In retrospect, although this activity was effective, the quick pace of the 4-wk unit, combined with the many assignments and activities that required higher-order thinking, was challenging for sophomores in the Biocore program. Many of the instructional staff believe that this activity and instructional approach would be more effective with more advanced undergraduate students (i.e., juniors or seniors in a molecular genetics course). In keeping with Biocore's inquiry-driven program goals, this unit has since been replaced with an investigative activity in which students pose and investigate their own hypotheses about heat-shock responses in C. elegans.

\section{Improvements to Assessment}

The assessment we performed would have been stronger had it focused more on actual, versus perceived, learning gains. Especially in the pre- and postsurveys, it would have been helpful to include more questions that assessed actual student learning. Also, some questions on student self-reports would have been more informative if they were worded more specifically. For instance, we asked students to "Rate your understanding of genotype vs. phenotype." A flaw with this question is that students may be confident in their ability to describe the difference between genotype and phenotype, but may not fully appreciate how one affects the other. A better question would be "Rate your understanding of how a change in genotype can affect the phenotype of an organism"; and it would be even better to ask students to provide their own concrete example of how a change in genotype can affect phenotype.

Also, since students were enrolled in the complementary lecture course at the same time, it is difficult to separate out the effects of lecture material versus lab material on student learning and confidence. Therefore, it would have been helpful to ask students in the postsurvey whether they felt that the laboratory strengthened their understanding of these topics beyond the level of understanding they attained from the lecture.

Finally, for the posters, it would have been more informative to use a rubric with a grading section for each learning objective, versus focusing on the content and quality of the sections. Despite these shortcomings, the assessment that was performed, as described in Results, does suggest that the laboratory activity was effective at promoting all five learning outcomes.

\section{Improvements to the Design of the Laboratory Exercise}

A major way this activity could be improved is to use genes with stronger deletion and/or RNAi phenotypes. Two of the genes we used have strong deletion allele phenotypes $(\mathrm{mlh}-1$ and cua-1) but the others did not. Many students expressed 
in the postsurvey that they wished the phenotypes were stronger and easier to observe: "The lab was interesting but at times it was difficult to understand what was happening because the phenotypes were often subtle and hard to distinguish." Although working with subtle phenotypes can be useful for honing observational skills, we do agree that using C. elegans strains with stronger phenotypes would be beneficial. One way this could be done is by relaxing the criterion of using orthologues of human disease genes. Orthologues share a common ancestral gene; homologues include both orthologues and paralogues, which arise from gene duplication and divergence.

Using homologues of human disease genes would allow for the use of strains with more dramatic phenotypes, which is likely to facilitate observations and to increase student appreciation for C. elegans as a model system. For instance, sma-1 is homologous to several human $\beta$-spectrins, which are implicated in numerous diseases, including hereditary spherocytosis. Homozygous sma-1(ru18) mutants have a 1754 basepair deletion and a dramatic phenotype in which worms are shorter and broader than wild-type C. elegans of the same age (McKeown et al., 1998). This phenotype is much easier to see and appreciate than the more subtle phenotypes exhibited by the $C$. elegans strains in the current activity. Additionally, we have identified several other genes that may be appropriate for use in this laboratory module (included in Supplemental Table 1). As an additional note, another way to increase student comfort with discerning C. elegans phenotypes would be to add an introductory session in which students use stereomicroscopes to examine worms with various phenotypes. This would aid in developing students' observational skills and likely increase student comfort with the exercise.

Another improvement would be to help students build an appreciation of how an organism like C. elegans can be used as a model for studying human disease processes. Our results showed strong student learning gains on this topic; however, there were some students who struggled with this concept. One student from Spring 2007 stated: "I didn't feel like it taught us too much about model organisms. It was great for learning the techniques in the laboratory, but putting everything together could be confusing at times." And another student from Spring 2008 remarked: "The link between worm phenotype and its significance in human research should be made much, much more clear." In subsequent runs of this exercise, we would like to try harder to reach students like these.

In both 2007 and 2008, students were given examples of how researchers are using $C$. elegans to study diseases such as Duchenne muscular dystrophy and polycystic kidney disease (Chamberlain and Benian, 2000; Culetto and Sattelle, 2000; Barr, 2005), and in 2008, a review article on the utility of model organisms (Barr, 2003), aptly titled "Super Models," was required reading and specifically discussed. Perhaps it would be more helpful to give students the task of finding examples on their own of how model organisms are being used to research disease processes and to follow up with a class discussion to share the information students find. Discovering this knowledge on their own may help students grasp the importance of model organisms in disease research.

Another important point is that the exercise as it stands emphasizes the relationship between genotype and phenotype in C. elegans. All of the laboratory activities and exercises are performed on C. elegans and do not involve direct analysis of the corresponding human gene. To answer the question, "Is C. elegans a good model system for investigating the function of your assigned human disease gene?," students relied on information gained through their experiments, in class discussions, and via literature research they performed outside class. One way to expand this activity would be to include additional exercises that involve analysis of the corresponding human disease gene. For instance, sequence analysis could be performed to determine the conservation between the $C$. elegans gene and the corresponding human gene. Also, class time could be spent to research disease phenotypes associated with the human gene under study. This would help students formulate a more solidly supported response to the question at hand.

As mentioned above, because of the challenging nature of this exercise, it may be more effective with junior or senior undergraduates. With more time, and advanced undergraduate students, it may even be feasible for students to identify human disease-associated genes that they would like to characterize in C. elegans on their own, using the methods described here. This would add a strong element of studentinspired experimental design and could also form the solid basis of an independent undergraduate research project.

In summary, we have presented a feasible, cost-effective, and challenging laboratory exercise that takes an integrative approach to understanding how a model organism can be used to study the basis of human disease. It is our hope that the work presented here will be useful to others involved in designing and instructing molecular genetics laboratory courses.

\section{ACKNOWLEDGMENTS}

We thank the diligent and talented Biocore students who participated in this activity. We also thank Seth McGee for his patience and technical assistance, Carol Borcherding for her help in compiling demographic data, and Jeff Hardin for reagents and encouragement. This work was supported in part by National Science Foundation grant IOB0518081 to Jeff Hardin and National Institutes of Health grant R15-HD059952 to E.A.C.-P. All research reported here was approved by the University of Wisconsin-Madison Institutional Review Board (IRB SE-2008-0768)

\section{REFERENCES}

Almeida CA, Tardiff DF, De Luca JP (2004). An introductory bioinformatics exercise to reinforce gene structure and expression and analyze the relationship between gene and protein sequences. Biochem Mol Biol Educ 32, 239-245.

Andersen J, Krichevsky A, Leheste JR, Moloney DJ (2008). Caenorhabditis elegans as an undergraduate educational tool for teaching RNAi. Biochem Mol Biol Educ 36, 417-427.

Barr MM (2003). Super models. Physiol Genomics 13, 15-24.

Barr MM (2005). Caenorhabditis elegans as a model to study renal development and disease: sexy cilia. J Am Soc Nephrol 16, 305-312.

Batzli J (2005). A unique approach? Four semesters of biology core curriculum. Cell Biol Educ 4, 125-128.

Brame CJ, Pruitt WM, Robinson LC (2008). A molecular genetics laboratory course applying bioinformatics and cell biology in the context of original research. CBE Life Sci Educ 7, 410421. 
Calixto A, Chelur D, Topalidou I, Chen X, Chalfie M (2010). Enhanced neuronal RNAi in C. elegans using SID-1. Nat Methods 7, 554-559.

Chamberlain JS, Benian GM (2000). Muscular dystrophy: the worm turns to genetic disease. Curr Biol 10, R795-R797.

Culetto E, Sattelle DB (2000). A role for Caenorhabditis elegans in understanding the function and interactions of human disease genes. Hum Mol Genet 9, 869-877.

Fields S, Johnston M (2005). Cell biology. Whither model organism research? Science 307, 1885-1886.

Fire A, Xu S, Montgomery MK, Kostas SA, Driver SE, Mello CC (1998). Potent and specific genetic interference by double-stranded RNA in Caenorhabditis elegans. Nature 391, 806-811.

Griffin V, McMiller T, Jones E, Johnson CM (2003). Identifying novel helix-loop-helix genes in Caenorhabditis elegans through a classroom demonstration of functional genomics. Cell Biol Educ 2, 51-62.

Honts JE (2003). Evolving strategies for the incorporation of bioinformatics within the undergraduate cell biology curriculum. Cell Biol Educ 2, 233-247.

Hurd DD (2008). A microcosm of the biomedical research experience for upper-level undergraduates. CBE Life Sci Educ 7, 210219.

Kennedy S, Wang D, Runkun G (2004). A conserved siRNAdegrading RNase negatively regulates RNA interference in C. elegans. Nature 427, 645-649.

Lissemore JL, Lackner LL, Fedoriw GD, De Stasio EA (2005). Isolation of Caenorhabditis elegans genomic DNA and detection of deletions in the unc-93 gene using PCR. Biochem Mol Biol Educ 33, 219 226.
McKeown C, Praitis V, Austin J (1998). sma-1 encodes a $\beta_{\mathrm{H}}$-spectrin homolog required for Caenorhabditis elegans morphogenesis. Development 125, 2087-2098.

Mello CC, Conte D, Jr. (2004). Revealing the world of RNA interference. Nature 431, 338-342.

Miller JA, Witherow DS, Carson S (2009). A laboratory-intensive course on RNA interference and model organisms. CBE Life Sci Educ 8, 316-325.

National Research Council (2003). BIO2010: Transforming Undergraduate Education for Future Research Biologists, Washington, DC: National Academies Press.

Phillips AR, Robertson AL, Batzli J, Harris M, Miller S (2008). Aligning goals, assessments, and activities: an approach to teaching PCR and gel electrophoresis. CBE Life Sci Educ 7, 96-106.

Powell JR, Kim DH, Ausubel FM (2009). The G protein-coupled receptor FSHR-1 is required for the Caenorhabditis elegans innate immune response. Proc Natl Acad Sci USA 106, 2782-2787.

Robertson AL, Phillips AR (2008). Integrating PCR theory and bioinformatics into a research-oriented primer design exercise. CBE Life Sci Educ 7, 89-95.

Simmer F, Tijsterman M, Parrish S, Koushika SP, Nonet ML, Fire A, Ahringer J, Plasterk RH (2002). Loss of the putative RNA-directed RNA polymerase RRF-3 makes C. elegans hypersensitive to RNAi. Curr Biol 12, 1317-1319.

Timmons L, Court DL, Fire A (2001). Ingestion of bacterially expressed dsRNAs can produce specific and potent genetic interference in Caenorhabditis elegans. Gene 263, 103-112.

Timmons L, Fire A (1998). Specific interference by ingested dsRNA. Nature 395, 854 